\title{
Las Crónicas de Don Bustos Domecq"
}

Conocíamos a Bustos Domecq como el autor de Seis problemas para don Isidro Parodi y Dos fantasías memorables. Sus crónicas nos llegan ahora bajo la firma de J. L. B. y A. Bioy Cásares. El detalle no es solamente técnico. La creación de autores ficticios y obras apócrifas es un viejo recurso de la ficción de todos los tiempos. Lo que hace del artificio un tópico borgeano es el hecho de que esos seres inventados coexisten y alternan con Ezequiel Martinez Estrada, Enrique Amorim, Alfonso Reyes o el propio J. L. B. Borges convierte, así, lo real y lo irreal en una realidad nueva para cuya vigencia sus progenitores son absolutamente prescindibles. $i Y$ si uno de esos seres del tercer mundo saltara de las páginas del libro, de las fronteras de su nueva realidad, para incorporarse al primero de esos mundos, a una realidad histórica donde se encontraran el soñador y el soñado? Es lo que, en efecto, ocurre. Bustos Domecq no es ni Borges ni Bioy Cásares. Es una tercera persona que sólo tiene de sus progenitores los nombres de sus tatarabuelos: Bustos de Borges, y Domecq de Bioy. Interrogado sobre sus obras en colaboración con Bioy, Borges ha explicado en una entrevista para la revista Paris Review:

When we write together what comes of the writing, if we are successful, and sometimes we are, what comes out is something quite different from Bioy Casares' stuff and my stuff, even the jokes are different. So we have created between us a kind of third person; we have somehow begotten a third person that is quite unlike us. A fantastic author with this likes, his dislikes and a personal style that is meant to be ridiculous; but still, it is a style of his own, quite different from the kind of style I write when I tried to create a ridiculous character... Once the story is written,

\footnotetext{
* Jorge Luis Borges y Adolfo Bioy Cásares. Crónicas de Bustos Domecq.
} Buenos Aires, Losada, 1967 . 
if you ask us whether this adjective or this particular sentence came from Bioy or from me, we can't tell.

No se trata, pues, de Don Quijote oyendo "las nuevas de sí mismo puestas en libro", o de Augusto Pérez increpando a Unamuno hacia el final de Niebla, o de un mago que en sus sueños procrea otro mago como en "Las ruinas circulares". Bustos Domecq es un autor cuya obra tiene muy poco que ver con la obra de Borges y la de Bioy, y si es cierto que se debe a la imaginación de sus procreadores también es cierto que los trasciende hasta convertirse en escritor que solamente (hasta dondé esto sea posible afirmar respecto a todo escritor) se debe a sí mismo. Bustos Domecq, cuyas crónicas, problemas y fantasías no son menos reales y "ubicuos" que las novelas de Bioy y los cuentos de Borges, sería, entonces, "una intrusión del mundo fantástico en el mundo real". Su caso no se diferencia sino en magnitud con ese otro milagro que Borges describe para explicar al autor de las Rubaiyat:

De la fortuita conjunción de un astrónomo persa que condescendió a la poesía, de un inglés excéntrico que recorre, tal vez sin entenderlos del todo, libros orientales e hispánicos, surge un extraordinario poeta, que no se parece a los dos.

Las crónicas están dedicadas a temas varios: la televisión, la radio; la historia, el arte (pintura, escultura, arquitectura, cocina), pero en su mayor parte tratan, como era de esperar, de la literatura y la crítica literatia. La printera, "Homenaje a César Paladión", parece por momentos aludir a Lugones: se habla de un plagio de Los parques abandonados que recuerda de inmediato la querella Lugones-Herrera. Pero Bustos Domecq evita esa facilidad cuando dice que Paladión "prefería Los crepuisculos del jardin de Lugones a Los parques abandonados". Más que una cargada a un escritor en particular, la crónica arremete contra posturas, hábitos y prácticas de ese escritor argentino (y no-argentino) que para escribir "se pone cuello duro" (son palabras de Cortázar). El estilo de Bustos Domecq es lo más logrado de esta crónica y de las subsiguientes. Podríamos ceñir más la cuerda y decir que las crónicas deben su realidad (humor, guiño sardónico, ironía, sarcasmo, deliciosa causticidad, broma a labio partido, etc.) al estilo con que están escritas. No importa si, a veces, alguien en particular se lleva los palos (en el caso de la crónica sobre C. Paladión se habla de "un crítico 
de considerable fuste", y luego "del panfletario, de cuyo nombre no quiero acordarme", que podría ser Blanco Fombona, el primero en acusar a Lugones del plagiar al uruguayo); la broma está dirigida más que a una perșona a esass sandeces que no son infrecuentes en "las literaturas hispánicas". Los resortes de ese estilo quedan ya descubiertos desde la dedicatoria del libro: "A esos tres grandes olvidados: Picasso, Joyce, Le Corbussier": un oxímoron del tamaño de los ilustres nombres a los cuales se aplica (más adelante se habla de "Homero, escritor de nota"). Las posibilidades estilísticas (y a veces estructurales) del oxímaron han sido fina e ingeniosamente aprovechadas por Borges en no pocos lugares de su obra. El mecanismo que produce gran parte del humor de las crónicas es, en esencia, oximorónico. El "estilo ridículo" de don Bustos (según definición de Borges) se nutre de ese lenguaje "que ninguno habla y que si a veces gusta; es precisamente por su aire exagerativo y caricatural, por lo forastero que suena". Un lenguaje almidonado, hecho de clichés, hábitos y cursilerías peto que don Bustos usa, justamente, para exorcizar ese estilo "indecidor" y acartonado, casticísimo y decimónicamente contemporáneo. El estilo de don Bustos es el antídoto más eficaz contra ese español de "sueñera mental" porque está hecho con los mismos ingredientes de ese veneno que ha traído tanta muerte a tanta página y tanto libro hispánico. El humor se produce porque ese estilo de cuello duro puede verse, observarse, en el espejo (ligeramente cóncavo) de las crónicas de don Bustos. Y, claro, nos reímos hasta la carcajada, advirtiendo (o sin advertir) que nos estamos riendo de tanta página ilustre que ha entrado muy dignamente en historias y manuales. Un ejemplo de resabio novecentista, que para más de un escritor de nuestro muy entrado siglo $\mathrm{xx}$ es todavía "recurso" literario, es el empleo del enclítico que pareciera decirnos "ojo, me estoy almidonando": don Bustos escribe "fumólo", "dijérase", "apresúrome", "congratulélo" (casi un trabalenguas), "jáctome", etc. ¿Quién se animará, después de don Bustos, a echar mano del enclítico sin arriesgarse a que una risotada lo interrumpa en lo más grave del discurso (escrito) ? De la misma manera, la prosa de don Bustos despliega un florilegio de expresiones idiomáticas que pueden llenar de orgullo al casticista más copetudo: "ni corto ni perezoso", "a tambor batiente", "con pie de plomo", "sin prisa pero sin pausa", "de cabo a räbo", "en sus trece", "poner en brete", "agua de borrajas", "Más allá de las narices". Tampoco falta algún arcaísmo de prestigio "rancio": "Tristura", "aqueste", "estotro". Está presente, por supuesto, el extranjerismo de lujo, dirigido a amedrentar 
al inocente lector, como diciéndole "sali de ahí, ignaro": "succès d'estime", "tramway", "non bis in idem", "not least", "la petite histoire", "soto voce", "in toto", "horresco referens", etc.

La segunda crónica es una tomadura de pelo a los escritores y novelas "realistas". Borges y Bioy se cuentan entre los escritores argentinos que más cáusticamente atacaron el realismo lastroso de la novela argentina de las primeras décadas del siglo. En 1944 Borges decía de la novela sicológica que "no ignora que a la una se almuerza, que a las cinco y media se toma el té, que a las nueve se come, que el adulterio puede ser vespertino, que la orografía de Córdoba no carece de toda relación con los veraneos, que de noche se duerme, que para trasladarse de un punto a otro hay diversos vehículos, que es dable conversar por teléfono, que en Palermo hay árboles y un estanque". La crónica "Una tarde con Ramón Bonavena" es una ingeniosa elaboración de este juicio. Puede aludir a un escritor en particular (ya aparecerá quien se dedique con lupa y escalpelo a encontrar la solución a la adivinanza - si la hay), pero es más sensato pensar que está dirigida a un tipo de escritor no infrecuente en "las literaturas hispánicas". El proyecto de Bonavena es escribir una novela realista, "de la tierra, sencilla, con personajes humanos y la consabida protesta contra el latifundio". Pero, ¿cómo novelar la realidad de Ezpeleta (el pueblo de Bonavena) sin exponerse a un juicio por calumnias?, "Cómo meterme en la cabeza de mi vecino?, ¿Cómo adivinar lo que piensan otros, sin renunciar al realismo?". Bonavena opta por una novela de animales domésticos, pero "¿cómo intuir los procesos cerebrales de un perro, cómo entrar en un mundo acaso menos visual que olfativo?". Una tercera posibilidad es la autobiografía, pero "¿quién soy yo? ¿El de hoy, vertiginoso, el de ayer, olvidado, el de mañana, imprevisible? ¿Qué cosa más impalpable que el alma?". Bonavena escoge, finalmente, "un sector limitado" de la realidad: novela "el ángulo de la mesa de pinotea en que (él) trabajaba, a cuyo propósito dedica cinco volúmenes "in octavo", de los cuales el quinto tiene 941 páginas.

El "naturalismo al día" sigue el regodeo a costa de un realismo convertido ahora en "descriptivismo". Ejemplos elocuentes de esta "escuela descriptivista argentina" no faltan: "el primer monumento" es una obra de crítica de la Divina Comedia del crítico "objetivo" Hilario Lambkin Formento; el estudio es de una fidelidad y meticulosidad geniales: ni hasta la más nimia preposición difiere del poema de Dante. Más ilustrativo todavía es el caso del poeta Urbas; en el certamen lite- 
rario de la editorial Destiempo, dedicado al tema "clásico y eterno" de la rosa, el jurado proclamó vencedor unánime a Urbas "que remitió, sencillo y triunfador... una tosa". Los estragos de un realismo de vuelo tan corto que nunca termina de despegar quedan, asi, reducidos al absurdo. De esta reducción emerge el humor y la sorna de las jugosas crónicas de don Bustos, narradas con un tono de voz que es en no menor medida otra reducción al absurdo de un estilo contrahecho a base de distinguidos lugares comunes. En varias crónicas don Bustos se ocupa de otro de los flacos de las letras hispánicas: la crítica. También aquí la prosa va definiendo la esclerotizada situación de nuestros críticos de fuste; don Bustos describe sus juicios consagratorios con fórmulas no menos consagradas y tópicas hasta la fatiga: "la realización más lograda de la novelística de la hora", "trazaremos a grandes rasgos un apretado panorama", "afirmaciones axiomáticas o perogrullescas", etc. La imagen palabrera, cursi, declamatoria e inútil constituye otra de las delicias del estilo derrochador (pero con conciencia de que en ese derroche se habrá agotado, al fin, la pobre vaca lechera) de don Bustos: "Quienes guardamos en la memoria, como en un estuche precioso, las disertas y caudalosas veladas...", "Estructurado cabalmente (el gremialismo) y dirigido por experto timón, constituirá la roca que se oponga al torrente de lava de la anarquía...", "Pincelemos con mayúsculas de oro los nombres que...", "los clarines de la fama", "no eran sino un dibujo en colores aplicado a la tabula rasa de su epidermis", "la larga paciencia de los siglos", etc. A estas imágenes manidas y cogotudas se agregan agresivos neologismos que traducen ese prurito de originalidad y esa obligada pedantería sin las cuales el literato de garra no merece llamarse tal (incluyendo el Borges martinfierrista, según declaración del su. sodicho); don Bustos escribe: "situacionar", "practicidad", "sonetístico", "impactar", "discusión alígera", "personajes protagónicos", "quehacer sartreril", "ojaladura", "claustrofobia", "indolora", "abstrusidades", etc. La acendrada pedantería (con trampa) de don Bustos no desaprovecha tampoco las egregias voces que le brinda el muestrario del idioma: "El escrúpulo nos impele a copiar la noticula subsiguiente...", "Dos años bastaron para que delectara la crítica un rasgo por demás singular...", "cuasi al final de mi ditirambo analítico", "Ahí me musitó su anteproyecto...". A veces un tiempo verbal se convierte en sutil rebuscamiento, no por eso menos efectivo para la prosa ringorranga de un erudito a la jazmín del cabo como don Bustos: "Piranesi falleciera en el interín..." o "Propios y extraños hubieron de reconocer, en su 
fuero interno..." En algunos casos el recargamiento llega a convertirse en frase elegantemente ripiosa o en tautología "lírica": "Todo ello retrotrae a la memoria, tan propensa a la amnesia...", "La fecha inau* gura1, me apersoné en acto de presencia...", "Tocante al título (del poes mario), Madrugar temprano comporta una moderna elipsis del secular y remozado refrán No por mucbo madrugar amanece más temprano, ya registrado por Correas en forma larval." Tampoco podía faltar en la castellanísima prosa de don Bustos una figura de linaje tan hispánico como el retruécano: "La muestra no rompió los viejos moldes; la inte: graban moldes de yeso..." Pero don Bustos Domecq no se conforma con las posibilidades registradas en las preceptivas; sabe rebasarlas inventando sus propios artificios. El más ingenioso, a nuestro inmodesto parecer, es la arbitraria intromisión de un elemento (nombre, expresión 9. advertencia) que al no condecir con su contexto más inmédiato cae sobre el lector: "como un balde de agua fría", pero tisiblemente refresçante: "El proyecto de sendos monumentos conmemorativos, contó con el unánime apoyo de las autoridades, de la opinión, de la banca, del turf, del clero, de los más reputados centros estéticos y gastronómicos y de Paul Eluard." "En primer término, el influjo avasallador de nombres cuyo genio no se discute: Esquilo, Aristófanes, Plauto, Shakespeare, Cal derón, Corneille, Goldoni, Schiller, Ibsen, Shaw, Florencio Sánchez:" "Quinientos ejemplares en papel pluma, numerados a todo escrúpulo, prácticamente integran la editio princeps $\mathrm{y}$, previo importe del abono en sonante y contante, se remitirán por correo, que anda como la mona." $Y$ un último ejemplo tomado de una nota al pie de página de la crónica "Ese polifacético: Vilaseco": "Para (su) identidad, consúltese el estudio "Una tarde con Ramón Bonavena", inserto en el indispensable vademecum Crónicas de Bustos Domecq (Buenos Aires, 1966), en venta en las buenas casas del ramo."

Don Bustos se las ingenia para conmover nuestros risotios cambiandó una o dos letras de reputados nombres; aunque estos nombres deben leerse en el contexto de la crónica los citamos, sin embargo, para ilustrar la técnica bustiana: Stuart Merrill, Monteiro Novato, el padre Feijoo $(¿ \mathrm{Ca}$ nal?), el doctor Gastambide, Farrel du Bosc, Gallach y Gasset, etc. Para agotar la lista de recursos y procedimientos de la prosa de don Bustos con criterio idóneo y responsabilidad profesional, sería menester transcribir el texto de las crónicas de pe a pa, palabra por palabra y coma por coma, tarea que excede - el lector comprenderá- nuestro propósito ( $y$ el de la revista). Habría que agregar, sin embargo, parafraseando un 
texto no menos memorable, que la prosa de don Bustos Domecq recoge la flor, la nata y la yerbabuena de la tradición hispánica y que por eso bien podría definirse, por su alabada hibridez, como una derivación clásico-barroca del modernismo, con inflexiones prosopopéyicas del siempre contemporáneo siglo XIX. Finalmente, y como ya sugerimos en líneas anteriores, esta prosa es eficacísimo antiveneno (de ahí su doble rebote que otros prefieren llamar oxímoron) contra los trasnochados Peredas, Montalvos, Larretas y Ortegas que continúan creciendo, con desusada perseverancia y racio-vitalismo desacostumbrado, en el jardín de nuestra literatura. (P. S.: He dicho)

Jaime Alazraki

University of California,

La Jolla. 
